\title{
Correction to: Risk management of emergency service vehicle crashes in the United States fire service: process, outputs, and recommendations
}

David P. Bui ${ }^{1 *}$, Keshia Pollack Porter ${ }^{2}$, Stephanie Griffin ${ }^{1}$, Dustin D. French ${ }^{3,4}$, Alesia M. Jung ${ }^{1}$, Stephen Crothers $^{5}$ and Jefferey L. Burgess ${ }^{1}$

\section{Correction}

After publication of the article [1], it has been brought to our attention that the second author's name was published incorrectly. Previously included as "Keshia P. Porter", the full and correct name should be "Keshia Pollack Porter". This has now been corrected in the original version of the article.

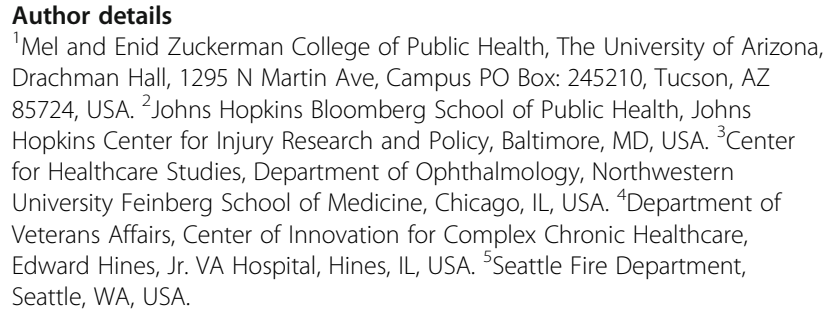

Received: 23 November 2017 Accepted: 27 November 2017

Published online: 01 December 2017

\section{Reference}

1. Bui D, Porter K, Griffin S, French D, Jung A, Crothers S, et al. Risk management of emergency service vehicle crashes in the United States fire service: process, outputs, and recommendations. BMC Public Health. 2017;17(1):885. https://doi. org/10.1186/s12889-017-4894-3.

\footnotetext{
* Correspondence: davidbui@email.arizona.edu

${ }^{1} \mathrm{Mel}$ and Enid Zuckerman College of Public Health, The University of Arizona, Drachman Hall, 1295 N Martin Ave, Campus PO Box: 245210, Tucson, AZ 85724, USA
} 